1. MBBS, MD (Gastroenterology)

Assistant Professor

Gastroenterology

Nawaz Sharif Medical College, University of Gujrat.

2. MBBS, FCPS (Cardiology)

Assistant Professor Cardiology

Nawaz Sharif Medical College,

University of Gujrat.

3. MBBS, FCPS (Gastroenterology) Senior Registrar

Aziz Bhatti Shaheed Teaching

Hospital, Gujrat.

4. MBBS, FCPS (Medicine)

Senior Registrar

Aziz Bhatti Shaheed Teaching

Hospital, Gujrat.

5. MBBS, FCPS (Medicine)

Senior Registrar

Aziz Bhatti Shaheed Teaching

Hospital, Gujrat.

6. MBBS

Medical Officer Medicine

Aziz Bhatti Shaheed Teaching

Hospital, Gujrat.

Correspondence Address:

Dr. Irfan Younus

Assistant Professor Gastroenterology

NSMC/ UOG Gujrat.

Aziz Bhatti Shaheed Teaching

Hospital,

Bhimbar Road, Gujrat.

irfanyounis7887@gmail.com

Article received on:

04/04/2020

Accepted for publication:

$15 / 06 / 2020$

\section{Burden and baseline characteristics of patients with decompensated liver disease in Tertiary Care Hospital Gujrat.}

\begin{abstract}
Irfan Younus' ${ }^{1}$, Muhammad Zahid Ali ${ }^{2}$, Muhammad Ajmal ${ }^{3}$, Hina Akhtar ${ }^{4}$, Javeria Ali ${ }^{5}$, Faiza Altaf ${ }^{6}$
ABSTRACT... Objective: To determine the load, clinical and laboratory findings of the patients with decompensated cirrhosis admitted in medical department of tertiary care hospital and to make plan for the improvement of these patients. Study Design: Cross Sectional study. Setting: Department of medicine of Aziz Bhatti Shaheed Teaching Hospital, Gujrat. Period: from $1^{\text {st }}$ January 2019 to $31^{\text {st }}$ March 2019. Material \& Methods: All 964 patients who were admitted included in study, clinical and laboratory features of patients with decompensated cirrhosis were recorded. Results: Male were in majority (53.7\%), median age was 39 years. Decompensated cirrhosis was found in 216 (22.4\%), patients due to complication of Diabetes Mellitus were $170(17.6 \%)$, COPD \& Asthma was found in 130 patients(13.5\%), Stroke \& Hypertension in 126 patients while Gastroenteritis $6 \%$ and infectious diseases RTI, UTI, Enteric Fever etc were present in 46 patients. Among 216 patients, one hundred \& seventy eight were Hepatitis C Positive, fifteen had Hepatitis B, and eight had history of alcohol consumption. Seven patients were both Hepatitis B and C positive while in 3.6\% etiology was other than mentioned above. Ascites was noted in two hundred six patients, $36.5 \%$ had variceal bleed while 51 admitted due to encephalopathy. Conclusion: HCV related cirrhosis and its complications like upper Gl bleed, encephalopathy, ascites and hepatoma are major burden on our hospitals and need special attention.
\end{abstract}

Key words: Ascites, Complications of Cirrhosis, Decompensated Cirrhosis, Hepatitis C, Hospitalization.

Article Citation: Younus I, Ali MZ, Ajmal M, Akhtar H, Ali J, Altaf F. Burden and baseline characteristics of patients with decompensated liver disease in Tertiary Care Hospital Gujrat. Professional Med J 2021; 28(2):165-170.

https://doi.org/10.29309/TPMJ/2021.28.02.4699

\section{INTRODUCTION}

Liver cirrhosis is a main cause of morbidity and mortality throughout the world. ${ }^{1,2}$ It is the terminal stage of progressive hepatic damage and fibrosis, in which liver parenchyma is distorted. ${ }^{2}$ Initially cirrhosis is compensated and majority of the patients are asymptomatic. They are usually discovered incidentally during investigation for other problems. Decompensation is usually defined as the presence of ascites, oesophageal/fundal variceal bleeding or hepatic encephalopathy in patients with compensated cirrhosis. ${ }^{3}$ These complications result in repeated admissions in hospital, poor quality of life, increased medical cost and poor prognosis. ${ }^{4}$ After decompensation, there is rapid increase in the morbidity and mortality in these patients, and 1-year fatality rate may rise up to $80 \%$ depending upon the reason of decompensation. ${ }^{5,6}$ The major causes of cirrhosis are chronic hepatitis like $\mathrm{B}$ and $\mathrm{C}$, alcoholic liver disease and nonalcoholic steatohepatitis (NASH). ${ }^{7}$ In advance stages cirrhosis is generally irreversible, while it is reversible in many cases after treating underlying pathology in compensated cirrhosis. ${ }^{8}$ Liver transplantation is the ultimate treatment of cirrhosis, but it is performed in limited number of patients due to high cost, shortage of donors and logistic problems. ${ }^{9}$ Prevention of Hepatitis $\mathrm{C}$ and management of these complications are necessary to reduce misery of these patients. According to World Health Organization (WHO), almost one hundred and seventy million people are suffering from Hepatitis C throughout the world. ${ }^{10}$ In different parts of Pakistan the prevalence ranges from $5-25 \% .{ }^{11}$ 
Despite cirrhosis is a global health problem, exact estimates of morbidity and mortality are not available, particularly at national levels, because lack of data recordings in many areas where cirrhosis is common and fatal. Mortality records due to cirrhosis are also scarce. ${ }^{12,13}$ In spite of the high prevalence of risk factors like Hepatitis $C$ for cirrhosis in Pakistan, there is no data available which show the burden of decompensated cirrhosis in our tertiary care hospitals. The aim of our study was to determine the burden and baseline characteristics of patients with decompensated cirrhosis in tertiary care hospital Gujrat and make plan to improve the management of these patients.

\section{MATERIAL \& METHODS}

This was a cross sectional study. All, 964 patients admitted in department of medicine of Aziz Bhatti Shaheed Teaching Hospital, Gujrat from first January 2019 to $31^{\text {st }}$ March 2019 were enrolled in study after taking informed consent. As there are separate indoor departments of cardiology and Chest Medicine so patients with Myocardial Infarction and Tuberculosis were not included in the study. Detailed history and clinical examination was done of all the patients. Baseline investigations like complete blood count, Blood sugar levels, liver function tests, renal function tests, HBsAg, Anti HCV, Anti HIV, prothrombin time, fasting lipid profile, urine analysis, X-Ray chest and ultrasound abdomen were performed of all the patients. Other special tests were also performed according to need of the patients. Patients having ascites, hepatic encephalopathy or upper GI bleed were labeled as decompensated cirrhosis which were 216 . The criterion of the international ascites club was used for grading of ascities as mild, moderate or severe. ${ }^{14}$ Hepatic encephalopathy was graded according to Burroughs crieteria. ${ }^{15}$ Endoscopy was performed to all the cirrhotics and esophageal varices were graded according to Beppuet al. ${ }^{16}$ Patients were categorized in different groups on the basis of primary diagnosis. Child Pugh scoring was used to assess the severity of liver diseases. ${ }^{17}$ Institutional Review Board of Nawaz Sharif Medical College approved the study.

\section{DATA ANALYSIS}

Statistical Packages for Social Sciences 16.0 for Windows was used for data analysis. Continuous variables such as age, laboratory tests like liver function and platelet counts etc were taken as medians (interquartile range). Groups of categorical variables were compared by using chi-square or Fisher's exact test. Mann-Whitney's rank sum test was applied to test meaningfully difference among medians of selected continuous variables. $P$ value of $<0.05$ was considered statistical significant.

\section{RESULTS}

Nine hundred and sixty four patients were admitted in department of medicine in three months. Male were in majority $(53.7 \%)$, mean age was $54.15+9.21$ years. Decompensated cirrhosis was found in $216(22.4 \%)$, patients due to complication of Diabetes Mellitus were 170 (17.6\%), COPD \& Asthma was found in 130 patients(13.5\%), Stroke \& Hypertension in 126 patients while Gastroenteritis $6 \%$ and infectious diseases RTI, UTI, Enteric Fever, malaria etc were present in 46 patients. Patients with joint pain were $3.9 \%$ (38), dyspepsia and gastroenteritis was in twenty six patients, different types of malignancies (stomach, lungs, pancreas, blood, colon) was noted in 26 (2.7\%) patients. Twenty two patients admitted due to work up of anemia, while psychiatric illness was found in $2.3 \%$ of cases. Other diagnosis like headache, epilepsy, cerebral palsy, migraine, oral or esophageal candidiasis, dengue fever, malabsorption syndrome, thyroid diseases etc were present among eighty two (8.5\%) patents.

Among 216 patients of decompensated cirrhosis, one hundred \& seventy eight(82.3\%) were Hepatitis C Positive, fifteen (7\%) had Hepatitis B, eight(3.6\%) had history of alcohol consumption. Seven(3.5\%) patients were both Hepatitis B and C positive while in 3.6\%(8) etiology was other than mentioned above.

Among 216 patients one hundred and twenty six (58.33\%) were male, ml8ean age was 50.15 +8.51 years. Ascites was noted in one hundred seventy seven (82\%) hospitalized patients. 
Hepatic encephalopathy was presentation of 108 patients, eighty two patients presented with upper GI bleed, spontaneous bacterial peritonitis was noted in $32 \%$ of the hospitalized patients with decompensated cirrhosis. Histories of surgery, blood transfusion, constipation was present in significant number of patients. Other findings like caput medusa, clubbing, palmer erythma and cyanosis were also observed in many patients who were described in table.

\begin{tabular}{|c|l|c|c|}
\hline Rank & \multicolumn{1}{|c|}{ Reason of Hospitalization } & Number of Patients & Percentage \% \\
\hline 1 & Decompensated cirrhosis & 216 & 22.4 \\
\hline 2 & Complicated Diabetes Mellitus & 170 & 17.6 \\
\hline 3 & COPD \& Asthma & 130 & 13.5 \\
\hline 4 & Stroke \& Hypertension & 126 & 13.1 \\
\hline 5 & Gastroenteritis & 58 & 6.0 \\
\hline 6 & Infections (RTI,UTI,Enteric fever etc) & 46 & 4.8 \\
\hline 7 & Rheumatological diseases & 38 & 3.9 \\
\hline 8 & Dyspepsia\& Gastroenteritis & 26 & 2.7 \\
\hline 9 & Malignancies & 26 & 2.7 \\
\hline 10 & Anemia & 24 & 2.5 \\
\hline 11 & Psychiatric illness & 22 & 2.3 \\
\hline 12 & Others & 82 & 8.5 \\
\hline
\end{tabular}

Table-I. Socio-demographic characteristics of the study population

\begin{tabular}{|c|l|c|c|}
\hline Rank & \multicolumn{1}{|c|}{ Cause of Cirrhosis } & No. of Patients & (\%) \\
\hline 1 & HCV Antibody Positive & 178 & 82.3 \\
\hline 2 & HBsAg Positive & 15 & 7.0 \\
\hline 3 & Alcoholics & 8 & 3.6 \\
\hline 4 & Both HBsAg\& Anti HCV Positive & 7 & 3.5 \\
\hline 5 & Others & 8 & 3.6 \\
\hline
\end{tabular}

\begin{tabular}{|c|c|c|c|}
\hline No & Clinical Features & No. of Patients & $\%$ \\
\hline 1 & Male Gender & 126 & 58.33 \\
\hline 2 & $\begin{array}{l}\text { Ascities } \\
\text { Moderate } \\
\text { Massive }\end{array}$ & $\begin{array}{l}177 \\
77 \\
100\end{array}$ & $\begin{array}{c}82 \\
43.50 \\
56.50\end{array}$ \\
\hline 3 & $\begin{array}{l}\text { Hepatic Encephalopathy } \\
\text { Grade I-II } \\
\text { Grade III-IV }\end{array}$ & $\begin{array}{l}108 \\
43 \\
65\end{array}$ & $\begin{array}{l}50 \\
20 \\
30\end{array}$ \\
\hline 4 & $\begin{array}{l}\text { Upper GI Bleed } \\
\text { Grade I-II } \\
\text { Grade III-IV } \\
\text { Fundal variceal bleed } \\
\text { Due to severe PHG }\end{array}$ & $\begin{array}{c}82 \\
22 \\
50 \\
6 \\
4\end{array}$ & $\begin{array}{c}38 \\
26.82 \\
60.97 \\
7.32 \\
4.88\end{array}$ \\
\hline 5 & Spontaneous Bacterial Peritonitis & 69 & 32 \\
\hline 6 & $\mathrm{Hx}$ of surgery & 69 & 32 \\
\hline 7 & $\mathrm{Hx}$ of constipation & 50 & 23 \\
\hline 8 & Caput Medusae & 47 & 23 \\
\hline 9 & $\mathrm{Hx}$ of blood transfusion & 43 & 20 \\
\hline 10 & Clubbing & 43 & 20 \\
\hline 11 & Palmer erythema & 39 & 18 \\
\hline 12 & Cyanosis & 22 & 10 \\
\hline
\end{tabular}

Table-III. Clinical features of patients with decompensated liver disease. 


\section{DISCUSSION}

Many studies have estimated the burden of cirrhosis at the global level in the past. The burden of chronic liver disease differs in different areas, races, sexes and economic status. In 1994, La Vecchia et $\mathrm{al}^{18}$ and in 2014, Mokdad et $\mathrm{al}^{19}$ done large studies on multiple countries having very large sample size to estimate mortality and morbidity due to this fatal disease. Both studies concluded that there is increase number of deaths and hospitalization of the patients with cirrhosis. Hepatitis C related liver cirrhosis is the major reason of hospitalization in tertiary care hospital of Gujrat. Now Hepatitis C has an effective cure rates due to increase availability of cheap generic medicine. ${ }^{20}$ It is expected that death rate for hepatitis $\mathrm{C}$ will reduce in near future if we are able to eradicate hepatitis $C$ by 2030, goal set by $\mathrm{WHO}^{21}$ Previously there was no national data available to see the disease burden of cirrhosis especially due to hepatitis C in medical wards of hospitals of Pakistan. Most of the patients remained ignorant of this infection until decompensation.

To manage this disease we should focus on early detection, awareness, vaccination and proper treatment so that progression and complications of this disease could be avoided. Our study showed that decompensated cirrhosis mainly due to hepatitis $C$ is the leading cause of admission to the general medical wards. Results are similar to another study which was conducted by us in Mayo Hospital Lahore, in which decompensation due to hepatitis C was found in $70 \%$ of the patients. ${ }^{22}$ In our study $7 \%$ of the cirrhosis was due to Hepatitis B which is favored by M.Ali et all in which prevalence of hepatitis B was 3-7 $\%$ in different areas and population groups of Pakistan. ${ }^{23}$ Ascites was present in $82 \%$ of the patients and more than half of patients had multiple complications, which increases the mortality and morbidity of patients.

These results are similar with findings of a study by Alvarez et al which ascites was commonest decompensation and 46 percent patients had more than one hepatic complication at admission. ${ }^{24}$ Similarly Almani et al reported that in Pakistan, ascites was present in 59\% of patients with cirrhosis followed by hematemesis $27 \%$ and hepatic encephalopathy in $9 \%{ }^{25}$ To reduce burden and deaths due to cirrhosis in our hospitals national health-care policy makers should know prevalence rates and deaths of each cause of cirrhosis to be able to make plan to improve the misery of patients due to cirrhosis.

\section{CONCLUSION}

Cirrhosis due to Hepatitis $C$ is the leading cause of hospitalization resulting in upper Gl bleed, encephalopathy, ascites and hepatoma. Hepatitis $\mathrm{C}$ infection is preventable and treatable condition. It is essential for policy makers to design comprehensive and cost effective preventive plans to reduce the burden of cirrhosis.

\section{CONFLICT OF INTEREST}

This study had no conflict of interest with other studies declared by any other author.

\section{Copyright $@ 15$ June, 2020.}

\section{REFERENCES}

1. Blachier $M$, Leleu $H$, Peck-Radosavljevic M, Valla DC and Roudot-Thoraval F. The burden of liver disease in Europe. A review of available epidemiological data. European Association for the Study of the Liver.2013; www.easl.eu/_eupolicy/eu-literature-review. Accessed 02 July 2013.

2. World Health Organization. Age-standardized death rates: Liver cirrhosis by country. 2013; http:/ / a pps .w h o .int/gho/da ta/ node.main. A1081? lang=en?showonly $=\mathrm{GISAH}$. Accessed 02 July 2013

3. Fleming KM, Aithal GP, Card TR, West J. The rate of decompensation and clinical progression of disease in people with cirrhosis: A cohort study. Aliment Pharmacol Ther 2010; 32: 1343-50.

4. Moreau R, Jalan R, Gines P, et al. Acute-on-chronic liver failure is a distinct syndrome that develops in patients with acute decompensation of cirrhosis. Gastroenterology 2013; 144: 1426-37.e1-9.

5. D'Amico G, Garcia-Tsao G, Pagliaro L. Natural history and prognostic indicators of survival in cirrhosis: A systematic review of 118 studies. J Hepatol 2006; 44: 217-31. 
6. Fleming KM, Aithal GP, Card TR, West J. All-cause mortality in people with cirrhosis compared with the general population: A population-based cohort study. Liver Int 2012; 32: 79-84.

7. Ge PS, Runyon BA. Treatment of patients with cirrhosis. N Engl J Med 2016; 375: 767-77.

8. Arthur MJ. Reversibility of liver fibrosis and cirrhosis following treatment for hepatitis C. Gastroenterology 2002; 122: 1525-28.

9. Van der Hilst CS, ljtsma AJ, Slooff MJ, Tenvergert EM. Cost of liver transplantation: A systematic review and meta-analysis comparing the United States with other OECD countries. Med Care Res Rev. 2009; 66:322.

10. Jamil MS, Ali H, Shaheen R, Basit A. Prevalence, knowledge and awareness of hepatitis C among residents of three Union Councils in Mansehra. $J$ Ayub Med Coll Abbottabad. 2010 Jul-Sep; 22(3):192-6.

11. Younus I, Sarwar S, Qaadir A, Butt Z, Nazir A, Choudry A. Correlation of literacy and awareness regarding hepatitis C: A survey of family members of hepatitis C patients'. Int J Med Res Rev 2016; 4(9):1576-81.

12. Asrani SK, Devarbhavi H, Eaton J, Kamath PS. Burden of liver diseases in the world. J Hepatol 2019; 70: $151-71$.

13. Asrani SK, Larson JJ, Yawn B, Therneau TM, Kim WR. Underestimation of liver-related mortality in the United States. Gastroenterology 2013; 145: 375-82. e1-2.

14. Moore KP, Wong F, Gines P, Bernardi M, Ochs A, Salerno $F$ et al. The management of ascites in cirrhosis. Report on the concensus conference of the international ascites club. Hepatology 2003; 38:258-266

15. Burroughs AK. Liver disorders -Management of chronic liver disease: In: Medicine International. 1990; Chapter 84:3472-3483.
16. Beppu K, Inokuchi K, Koyanagi N, Nakayama S, Sakata $\mathrm{H}$, Kitano $\mathrm{S}$ et al. Prediction of variceal hemorrhage by esophageal endoscopy. Gastrointest Endosc $1981 ; 27: 213-218$

17. Durand $F$ and Valla D. Assessment of prognosis of cirrhosis. Semin Liver Dis. 2008;28(1):110-122.

18. La Vecchia C, Levi F, Lucchini F, Franceschi S, Negri E. Worldwide patterns and trends in mortality from liver cirrhosis, 1955 to 1990. Ann Epidemiol 1994; 4: $480-86$

19. Mokdad AA, Lopez AD, Shahraz S, et al. Liver cirrhosis mortality in 187 countries between 1980 and 2010: A systematic analysis. BMC Med 2014; 12: 145.

20. Freeman JA, Hill A. The use of generic medications for hepatitis C. Liver Int 2016; 36: 929-32.

21. WHO. Combating hepatitis B and $\mathbf{C}$ to reach elimination by 2030 . May, 2016.

22. Younis, I., Sarwar, S., Butt, Z. et al, Clinical characteristics, predictors, and survival among patients with hepatopulmonary syndrome. Ann Hepatol. 2015; 14:354-360.

23. Ali M, Idrees M, Ali L, Hussain A, Rehman IU, Saleem $S$, Afzal S, Butt S. Hepatitis B virus in Pakistan: a systematic review of prevalence, risk factors, awareness status and genotypes. Virology journal. 2011 Dec 1;8(1):102.

24. Alvarez MA, Cirera I, Sola R, Bargallo' A, Morillas RM and Planas R. Long-term clinical course of decompensated alcoholic cirrhosis. A prospective study of 165 patients. J ClinGastroenterol 2011; 45:906-911.

25. Almani SA, Memon AS, Memon AL, Shah MI, Rahpoto $M Q$ and Solangi R. Cirrhosis of liver: Etiological factors, complications and prognosis. JLUMHS 2008; 61-66. 


\begin{tabular}{|c|l|l|l|}
\hline \multicolumn{3}{|c}{ AUTHORSHIP AND CONTRIBUTION DECLARATION } \\
\hline Sr. \# & Author(s) Full Name & \multicolumn{1}{|c|}{ Contribution to the paper } & Author(s) Signature \\
\hline 1 & Irfan Younus & $\begin{array}{l}\text { Concept, Data collection, Statistical } \\
\text { analysis, Design of study. } \\
\text { Critical revision of study, Data } \\
\text { collection. } \\
\text { Drafting, Data collection. }\end{array}$ \\
\hline 3 & Muhammad Zahid Ali \\
\hline 5 & Mina Akhtar & Javeria Ali & Critical revision, Data collection. \\
\hline 6 & Faiza Altaf & Data collection. \\
\hline
\end{tabular}

